\title{
A Survey about Surgical Preferences in Operative Technique in Decompressive Craniectomy in Traumatic Brain Injury
}

\author{
Hernando Raphael Alvis-Miranda, Gabriel Alcala-Cerra, Andres M Rubiano, Luis Rafael Moscote-Salazar
}

\begin{abstract}
Traumatic brain injury is a public health problem. The control of intracranial hypertension is a key strategy for managing this type of patients. Decompressive craniectomy is a measure of second level for the control of intracranial hypertension refractory to medical management. In order to assess trends in relationship to the management of decompressive craniectomy, a survey was designed and sent to neurosurgeons from various countries. We discuss the results for a better standardization of surgical techinique. Decompressive craniectomy is a saving technique and usefulness depend on a correct realization of the neurosurgical procedure.
\end{abstract}

Keywords: Neurotrauma, Decompressive craniectomy, Brain injury.

How to cite this article: Alvis-Miranda HR, Alcala-Cerra G, Rubiano AM, Moscote-Salazar LR. A Survey about Surgical Preferences in Operative Technique in Decompressive Craniectomy in Traumatic Brain Injury. J Trauma Critical Care Emerg Surg 2013;2(3):106-111.

Source of support: Nil

Conflict of interest: None

\section{RESUMEN}

La lesión cerebral traumática es un problema de salud pública. El control de la hipertensión intracraneal es una estrategia clave para la gestión de este tipo de pacientes. Craniectomía descompresiva es una medida de segundo nivel para el control de la hipertensión intracraneal refractaria al tratamiento médico. Con el fin de evaluar las tendencias en relación con la gestión de la craniectomía descompresiva, se diseñó una encuesta y se envió a los neurocirujanos de diversas países. Se discuten los resultados para una mejor estandarizactión de techinique quirúrgica. Craniectomia descompresiva es un ahorro téchnica y utilidad dependen de una correcta realización del procedimienot neuropuirúrgico.

Palabras claves: Neurotraumatológica, Craniectomia descompresiva, Brain lesión.

\section{INTRODUCTION}

Currently morbidity and mortality due to traumatic injuries are a well-recognized major public health problem. Similarly traumatic brain injury (TBI) is a major public health concern worldwide, according to the predictions, neurotrauma will account an increasing number of deaths worldwide by $2020 .{ }^{1}$ Unfortunatley, overall trauma ranks among the leading causes of death and occurs in all regions, affecting people in all age and income groups. ${ }^{2}$
Among the many problems that arise as a result of TBI, brain edema, and its consequence, intracranial hypertension (ICH), are a major cause of complications and death. Dramatically, TBI is the most common cause of $\mathrm{ICH}_{3}{ }^{3}$ and even more dramatically ICH is the most frequent cause of death and disability following severe TBI. ${ }^{4-6}$

Thus, it is comprehensible that neurosurgeons perform considerable effort to controlling intracranial pressure (ICP) in patients with TBI. Decompressive craniectomy (DC) has been advocated as one strategy for managing ICP. ${ }^{7}$

The aim of this work was to determine the surgical preferences when performing DC as a surgical management tool in TBI patients who have refractory ICH.

\section{MATERIALS AND METHODS}

An online survey creator (http://www.encuestafacil.com) was used to develop a web-based international structured survey. The survey invitations were sent by e-mail, and aimed neurosurgeons to meet their surgical management considerations in TBI patients who need DC. For ethical considerations, none of the neurosurgeons surveyed were identified. Answers from the survey were compiled and entered into an Excel database (Microsoft. Redmond. Washington). The data was analyzed by software 17.0 (SPSS. Inc., Chicago, IL), to determine the frequency distribution of each one of the variables.

\section{RESULTS}

We had a total of 33 surveyed neurosurgeons, from which $20(60.6 \%)$ actually work in the academic field, nine

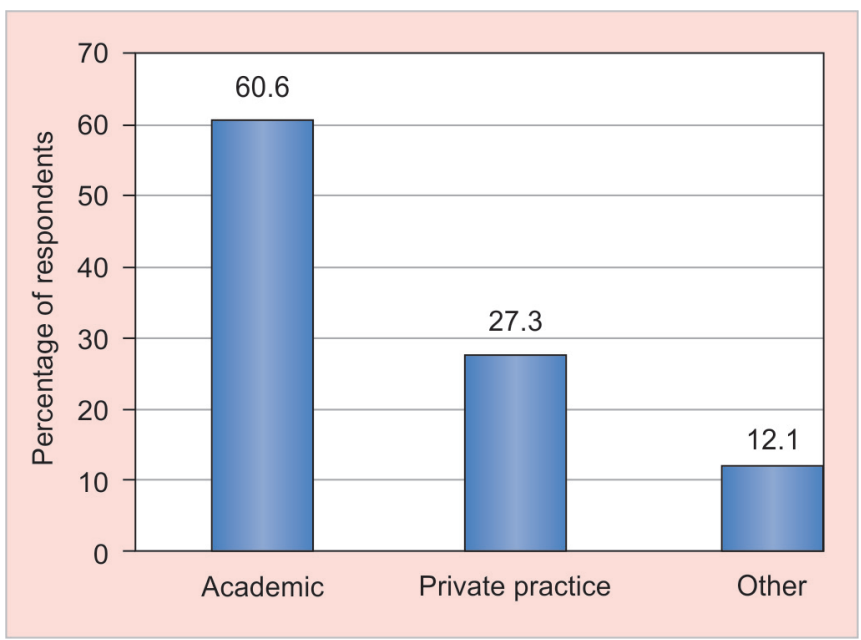

Graph 1: In what kind of a setting do you currently practice? 
$(27.3 \%)$ in private practice and just four $(12.15)$ in other areas (Graph 1). Their practice experience is a mean of $11.6 \pm 7$ years on practice.

When facing clinical situations which needed a DC, $19(57.6 \%)$ of the surveyed physicians opted for hemicraniectomy, $5(15.2 \%)$ focal craniectomy, and 4 (12.1\%) bilateral DC (Graph 2A). In general, 21 (63.6\%) performed a mean of $1 \mathrm{DC}$ per month, followed by $7(21.2 \%)$ physicians who performed 2 per month (Graph 2B).

During DC procedure, $12(36.4 \%)$ consider as the most important technical detail the craniectomy size. For 4 $(12.1 \%)$ it is the dural opening, and 14 (42.4\%) considered that the size of craniectomy, the dural opening, the surgical time and the blood loss are of equal importance when performing DC (Graph 2C).

\begin{tabular}{|l|c|}
\hline \begin{tabular}{|} 
Table 1: On average, do you use the 'vascular tunnel' to avoid \\
compression of cortical veins?
\end{tabular} \\
\hline & \begin{tabular}{c} 
Reported cases, $n=33$ \\
\hline Yes
\end{tabular} \\
\hline No & $24(24.2)$ \\
\hline Other Specify & $1(32.7)$ \\
\hline aAbsolute value (percent) & \\
\hline
\end{tabular}
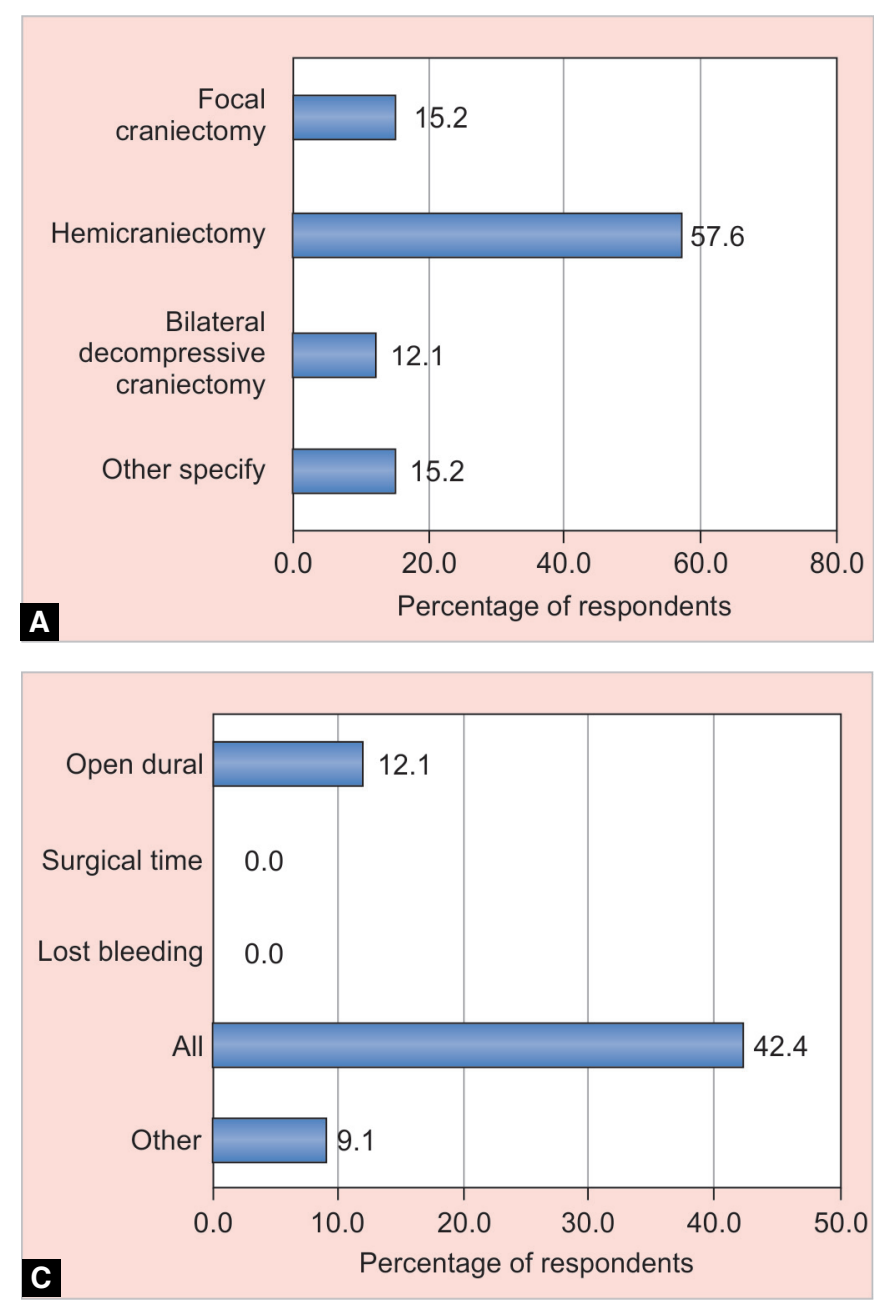

After DC, 17 (51.5\%) routinely monitor the ICP; 13 (39\%) do not and $3 \%$ only monitor ICP occasionally or just do not make monitoring because lack of equipment (Graph 2D).

When opting for bilateral DC, 22 (66.7\%) consider to prefer the bone resection over the whole hemisphere, including the temporal fossa, and posterior through a line connecting the tragus with the asterion. Ten (30.3\%) consider not to make the described approach and one $(3 \%)$ prefer other specifications (Graph 3A). During this type of DC, 25 $(75.8 \%)$ prefer to preserve a bone ridge over the superior longitudinal sinus (Graph 3B).

Regard the incision, $29(87.9 \%)$ is the standard for trauma, for two (6.1\%) is the LG Kempe Technique, and the rest perform other type of incisions (Graph 4).

\begin{tabular}{|l|c|}
\hline \multicolumn{2}{|c|}{$\begin{array}{c}\text { Table 2: In relation with the cranioplasty, do you usually do it in } \\
\text { patient with decompressive craniectomy? }\end{array}$} \\
\hline & \begin{tabular}{c} 
Reported cases, $n=33$ \\
\hline 1 month
\end{tabular} \\
\hline 3 months & $6(18.2)$ \\
\hline 6 months & $6(57.6)$ \\
\hline Other specifications & $2(18.2)$ \\
\hline${ }^{a}$ Absolute value (percent) & $2(6.1)$ \\
\hline
\end{tabular}
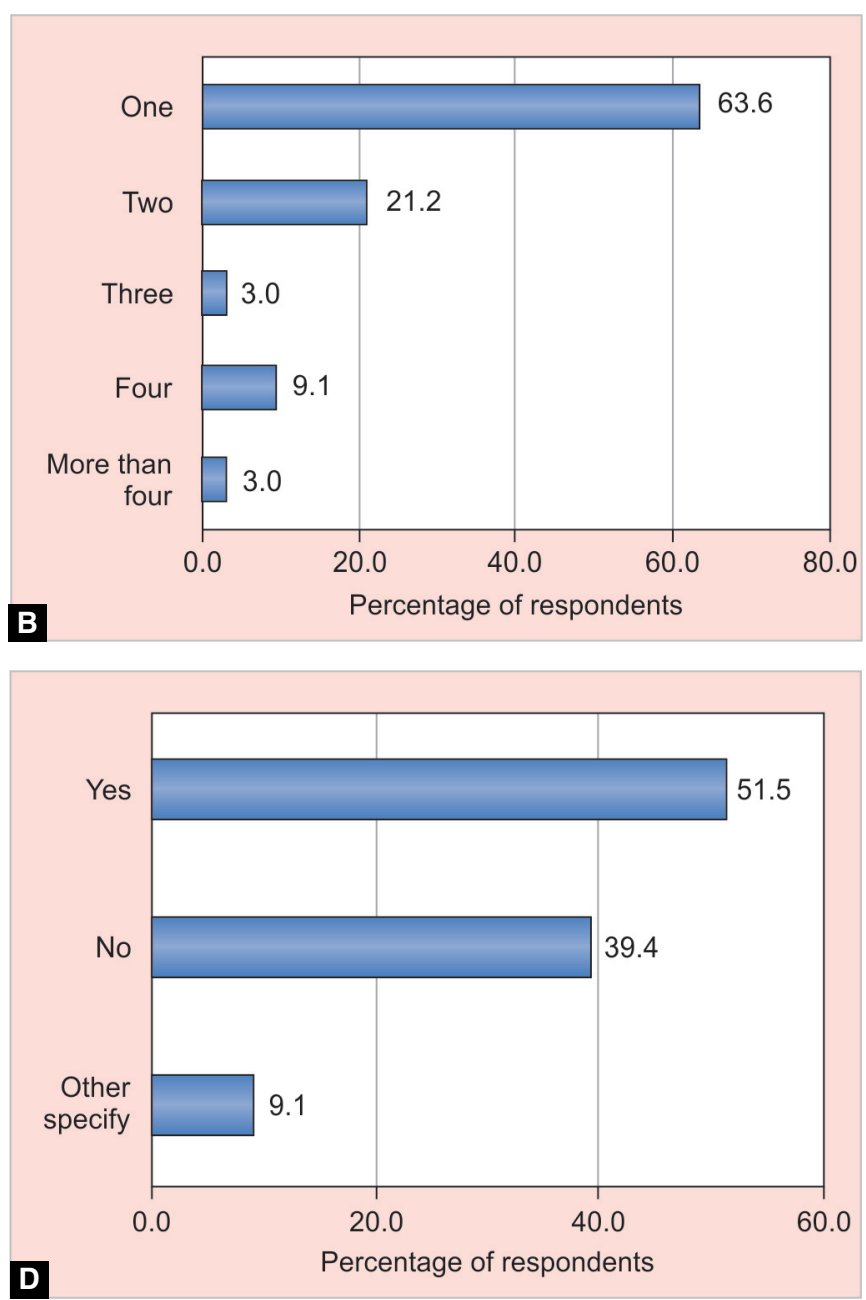

Graphs 2A to D: (A) Some preferences when performing DC, (B) mean DC performed at a month, (C) what is the most important aspect during DC and (D) ICP monitoring after DC 
Thirteen (39.4\%) affirm to perform the dural opening with an incision plus a pedicle on the middle meningeal artery; $12(36.4 \%)$ incise the dura in a radial fashion, and five (15.2\%) prefer the Bullock technique (Graph 5). When deciding the technique for the conservation of the bone flap, $15(45.5 \%)$ prefer to preserve it in the abdominal fat, eight $(24.2 \%)$ prefer simple freezing and four $(12.1 \%)$ choose to preserve it in an organ bank (Graph 6).

We inquired the surveyed physicians regarding the use of 'vascular tunnel' to avoid compression of the cortical veins, 24 (72.7\%) do not use it, eight (24.2\%) yes (Table 1), and in relation with the cranioplasty in DC, $19(57.6 \%)$ of the surveyed make it at 3 months after surgery, six $(18.2 \%)$ at the month, six (18.2\%) at the 6 months (Table 2).

\section{DISCUSSION}

Although, there are no widely accepted indications for $\mathrm{DC},{ }^{7}$ some indications for it are the unilateral lesions, such as unilateral swelling, contusions, extradural or subdural hemorrhage, midline shift; ${ }^{8}$ generally is required bifrontal

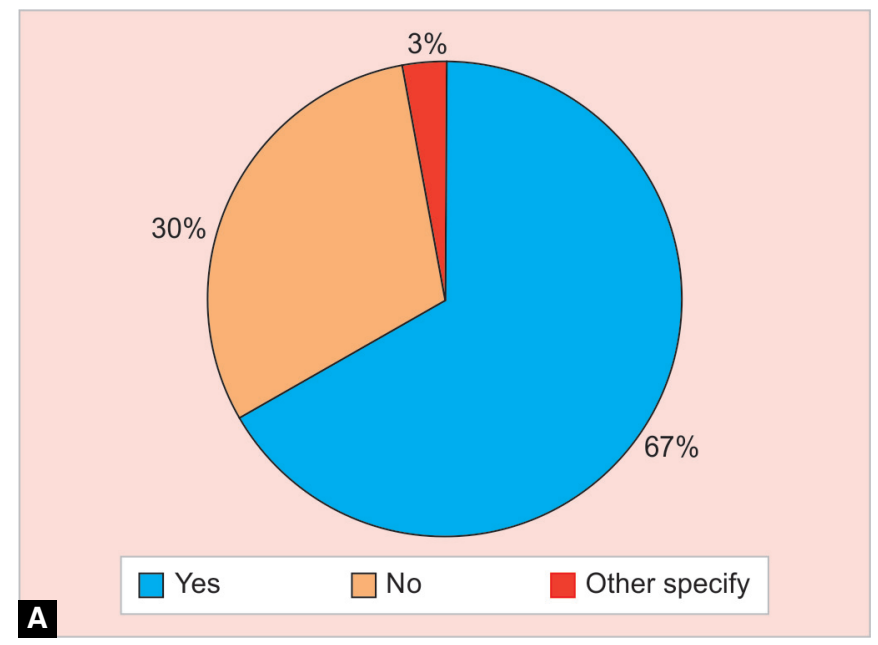

B

decompression for diffuse cerebral edema with no obvious midline shift. However, regard to TBI, according to the European Brain Injury Consortium and Brain Trauma Foundation guidelines for severe TBIs, DC should be incorporated to the second-tier therapeutic arsenal in patients with refractory ICH to first-tier therapeutic measures, ${ }^{9-12}$ i.e. when appropriate targeted surgery and medical treatment fails, DC is the option. ${ }^{13}$

As summarized above, the surveyed neurosurgeons when facing clinical situations in which is needed a DC, more than a half (57.6\%) opt to perform hemicraniectomy, $15.2 \%$ prefer focal craniectomy, and $12.1 \%$ the bilateral DC; but the ideal technique implies the removal of bone in the entire supratentorial hemicranium. One of the most important landmarks for this procedure is the root of the zygoma. It allows the identification the floor of the temporal fossa. Also these are important landmarks: the asterion (confluence of the lamboid, occipitomastoid, and temporoparietal sutures, indicates the area of transition between the transverse and sigmoid sinuses), the keyhole (identifies the pterion and

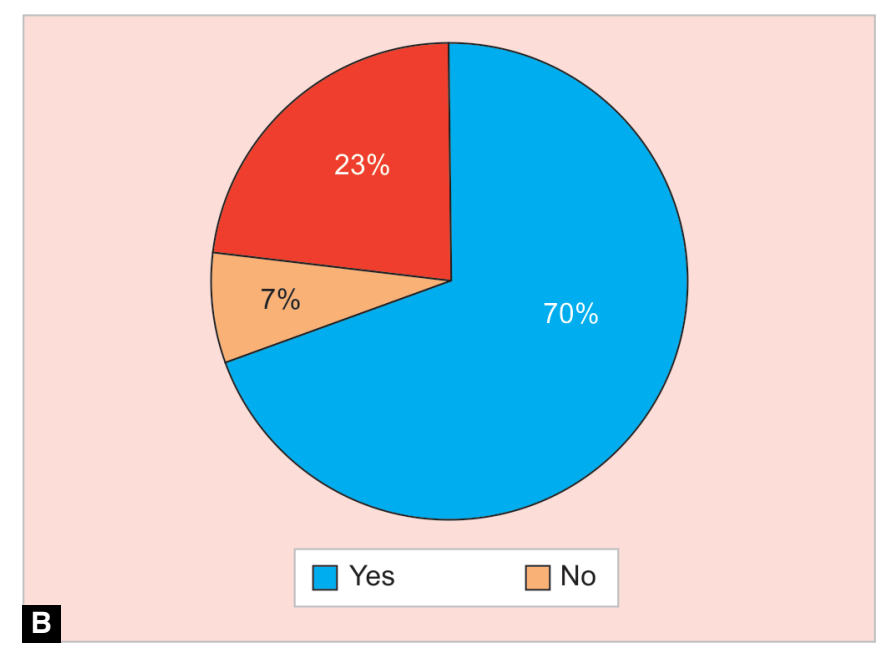

Graphs 3A and B: Approaches to bilateral DC

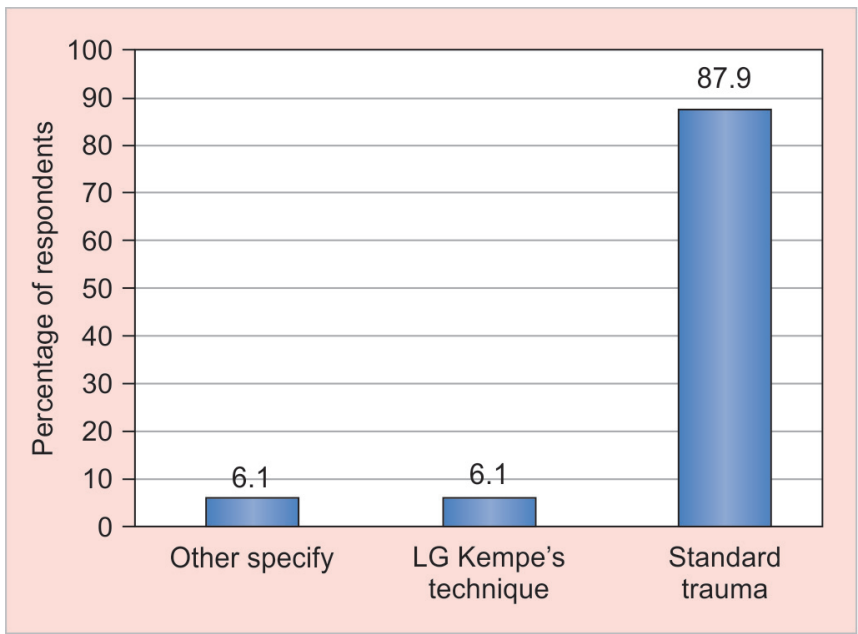

Graph 4: Technique of the skin incision in decompressive craniectomy

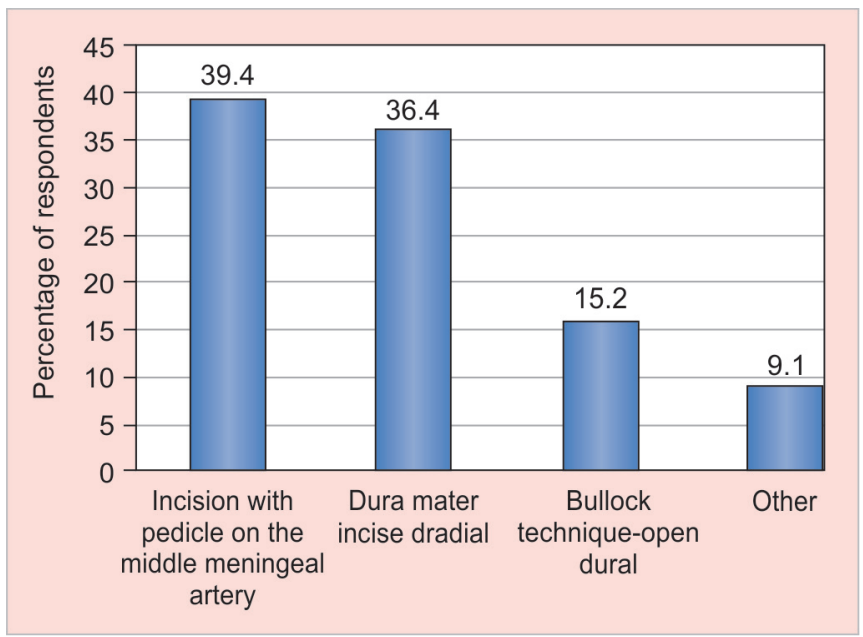

Graph 5: Dural opening technique for decompressive craniectomy 
indicates the location of the frontal, temporal, and orbital cavities), the inion, the glabella, and the midline (delineates the course of the superior sagittal sinus). ${ }^{14}$ Frontosubtempoparietooccipital DC with dural opening and enlargment with duraplasty is the most used decompressive technique, being the only technique that avoids brain herniation through the DC hole, and prevents venous infarctions that power brain swelling. ${ }^{11}$ Even when is not a surgical procedure frequently used, it still is in the neurosurgeon armamentarium for combating ICH. In our results we found that $63.6 \%$ perform a mean of $1 \mathrm{DC}$ per month, and $21.2 \%$ perform 2 per month.

Regard the incision, $87.9 \%$ perform the standard for trauma, $6.1 \%$ the LG Kempe Technique, and the rest perform other kind of incisions. Skin incisions for DC include the large reverse question mark frontotemporoparietal incision and the LG Kempe modified incision or midline sagittal incision with 'T-bar'; skin incisions for bilateral decompressive craniectomies include the performing of two hemicraniectomies or to perform the Kjellberg type DC (standard bicoronal incision).

Regard dural opening, 39.4\% affirm to perform it with an incision plus a pedicle on the middle meningeal artery; $36.4 \%$ incise the dura in a radial fashion, and $15.2 \%$ prefer the Bullock technique. For dural opening can be used different approaches that includes fish-mouth incision, stellate incision, C-shaped fashion incision and cruciate incision. ${ }^{15,16}$

When deciding the technique for the conservation of the bone flap, $45.5 \%$ prefer to preserve it in the abdominal fat, $24.2 \%$ prefer the simple freezing and the $12.1 \%$ choose to preserve it in the organ bank. Basically there are three options for dealing with the craniectomy bone flap. One is to discard it; another is to create a separate abdominal subcutaneous pocket to place the bone flap that will be accessed at the time of the cranioplasty; and the last is to preserve it in a

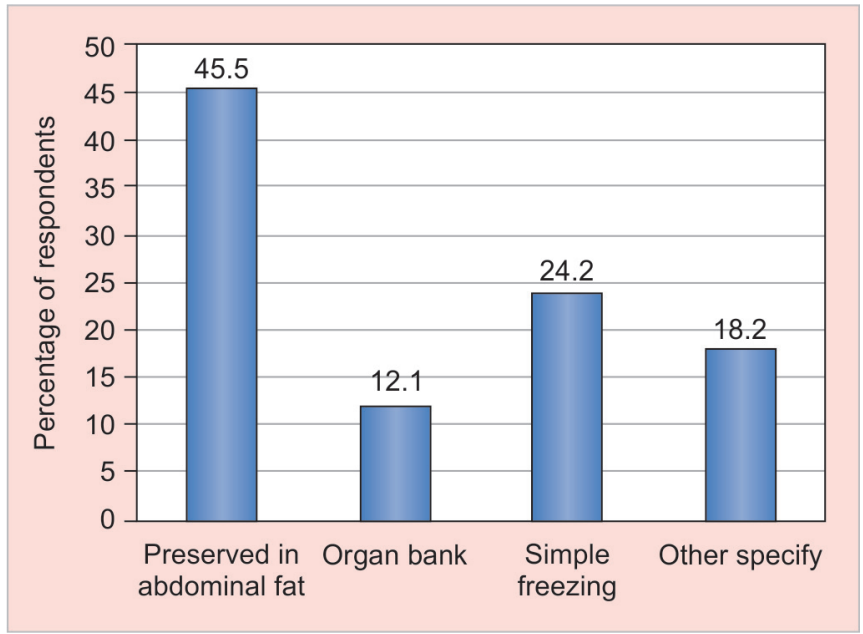

Graph 6: Technique of bone flap preservation tissue bank. ${ }^{7}$ Some institutions prefer to discard the flap, and thus requiring that the cranioplasty be performed with intraoperative reconstruction. When the bone flap is placed in the abdominal subcutaneous pocket, the body usually remolds the bone edges to some degree, leaving it knobby and slightly enlarged. Keeping the bone frozen in a bone bank is associated with excellent cosmetic outcomes. There is no risk of bone remodeling and replacement is easy. ${ }^{7}$

The choice of materials for grafting and dural substitution depends on the surgical goal, but reducing the potential for dural adhesion is critical. Dural grafts and antiadhesion barriers are important in minimizing these concerns and facilitating the follow-up dissection for cranioplasty. ${ }^{17}$

Extensive adhesions can often cause increased operative time, risk of dural violation, brain injury, and surgeon frustration during the cranioplasty. ${ }^{17}$ A surgeon can also expect to face greater difficulty with dissection of adhesions when the length between the first and second surgery is increased. ${ }^{17}$ It involves removing a large piece of the skull and opening the underlying dura to allow the brain to expand. In this way the brain swelling that causes ICH can be accommodated by increasing volume instead. ${ }^{18}$ Inappropriate techniques for DC, e.g. do not smooth the bony edges; do not try at maximum to do bone removal as large as possible, performing wrong approaches like only subtemporal decompression, or only frontotemporal decompression, can generate iatrogenic brain lesions, and even generate brain herniation trough the craniectomy defect.

During DC procedure, the $36.4 \%$ of the surveyed neurosurgeons consider as the most important technical detail the craniectomy size, for $12.1 \%$ is the dural opening, and for the $42.4 \%$ are the size of craniectomy, the dural opening, the surgical time and the bleeding lose. The truth is that an adequate bone flap size is a factor related to survival, as demonstrated by Tagliaferri et al, ${ }^{13}$ who found that large bone flap $(>12 \mathrm{~cm})$ is related to survival only in patients younger than 65 years, this means that should be used in younger patients, the population who more suffer TBI. Although not statistically significant, those patients with a large bone flap also had better outcome. Overall one to two thirds of the surviving patients have been reported to have a favorable outcome and the mortality has been reported to be less than $20 \%{ }^{19-32}$

In relation with the cranioplasty in DC, the $57.6 \%$ make it at 3 months after surgery, $18.2 \%$ at the month, and the $18.2 \%$ at the 6 months. Staging reconstruction of high-risk cranial defects followed by definitive cranial defect reconstruction improved the likelihood of implant retention and successful cranioplasty outcome. ${ }^{33}$ 
A pair of concern issues in the realization of DC are the protection of vascular structures and the ICP monitoring; in our inquiring regard to the use of 'vascular tunnel' to avoid compress the cortical veins, the $72.7 \%$ do not use it, $24.2 \%$ do it. After DC, $51.5 \%$ routinely monitories the ICP; $39 \%$ do not use it, and the $3 \%$ resting only monitories ICP occasionally or just do not make monitoring because lack of equipment, thus even when DC is a measure for salvation of brain parenchyma, it does not means that always will resolve the problem, the edema can be extensive, expanding and converting in a diffuse lesion, in the context of a bad DC (i.e. a small DC defect, no smoothing of bony edges, etc.), will affect patients outcome, even resulting in death.

\section{CONCLUSION}

The results of our international survey confer to us a varied information regard the use of DC in TBI. When DC is indicated in TBI patients, its performance should not be discussed but applied. DC is a reserve armamentarium that possesses the neurosurgeon for controlling refractory ICH to first-tier therapeutic measures. Unfortunately the usefulness of DC can be affected by the fact of performing DC out of the strict sense of its technique, as described above. Thus, standardizing DC will be possible to reach at a maximum its utility in TBI, when standardized its size, incisions, the dural opening, and the cranioplasty in terms of time and mechanism for performing it, in that moment all information regard DC will be completely comprehensible, impacting on its best use and performing. Yet all patients' needs should be considered on an individual basis, this standardization will render in a best outcome and prognosis for TBI patients with refractory ICH. Given these statistics, proper use of DC in TBI patients is an important priority in the neurosurgery education.

\section{REFERENCES}

1. Murray CJ, Lopez AD. Alternative projections of mortality and disability by cause 1990-2020: Global Burden of Disease Study. Lancet 1997;349:1498-1504.

2. Hyder AA, Aggarwal A. The increasing burden of injuries in Eastern Europe and Eurasia: making the case for safety investments. Health Policy 2009;89:1-13.

3. Little RD. Increased intracranial pressure. Clinical pediatric Emergency Medicine 2008;9:83-87.

4. Clifton GL, Miller ER, Choi SC, Levin HS. Fluid thresholds and outcome from severe brain injury. Crit Care Med 2002;30: 739-745.

5. Juul N, Morris GF, Marshall SB, Marshall LF. Intracranial hypertension and cerebral perfusion pressure: influence on neurological deterioration and outcome in severe head injury. The Executive Committee of the International Selfotel Trial. J Neurosurg 2000;92:1-6.
6. Marmarou A. Increased intracranial pressure in head injury and influence of blood volume. J Neurotrauma 1992;9 Suppl 1:S327-332.

7. Holland M, Nakaji P. Craniectomy: surgical indications and technique. Operative Techniques in Neurosurgery 2004;7:10-15.

8. Li LM, Timofeev I, Czosnyka M, Hutchinson PJA. Review article: the surgical approach to the management of increased intracranial pressure after traumatic brain injury. Anesth Analg 2010;111:736-748.

9. Maas AI, Dearden M, Teasdale GM, Braakman R, Cohadon F, Iannotti F, Karimi A, Lapierre F, Murray G, Ohman J, Persson L, Servadei F, Stocchetti N, Unterberg A. EBIC-guidelines for management of severe head injury in adults. European Brain Injury Consortium. Acta Neurochir (Wien) 1997;139:286-294.

10. The brain trauma foundation. The American Association of Neurological Surgeons. The Joint Section on Neurotrauma and Critical Care. Guidelines for cerebral perfusion pressure. J Neurotrauma 2000;17:507-511.

11. Lubillo S, Blanco J, López P, Molina I, Domínguez J, Carreira L, Manzano JJ. Role of decompressive craniectomy in brain injury patient. Med Intensiva 2009;33:74-83.

12. Lubillo S, Blanco J, López P, Domínguez J, Ruiz C, Molina I, Morera J. Does decompressive craniectomy improve other parameters besides ICP? Effects of the decompressive craniectomy on tissular pressure? Med Intensiva 2011;35: 166-169.

13. Tagliaferri F, Zani G, Iaccarino C, Ferro S, Ridolfi L, Basaglia N, Hutchinson P, Servadei F. Decompressive craniectomies, facts and fiction: a retrospective analysis of 526 cases. Acta Neurochir (Wien) 2012;154:919-926.

14. Quinn TM, Taylor JJ, Magarik JA, Vought E, Kindy MS, Ellegala DB. Decompressive craniectomy: technical note. Acta Neurol Scand 2011;123:239-244.

15. Ragel BT, Klimo P, Martin JE, Teff RJ, Bakken HE, Armonda RA. Wartime decompressive craniectomy: technique and lessons learned. Neurosurg Focus 2010;28:E2.

16. Johnson RD, Maartens NF, Teddy PJ. Technical aspects of decompressive craniectomy for malignant middle cerebral artery infarction. J Clin Neurosci 2011;18:1023-1027.

17. Mumert ML, Altay T, Couldwell WT. Technique for decompressive craniectomy using Seprafilm as a dural substitute and anti-adhesion barrier. J Clin Neurosci 2012;19:455-457.

18. Mitchell P, Gregson BA, Vindlacheruvu RR, Mendelow AD. Surgical options in ICH including decompressive craniectomy. J Neurol Sci 2007;261:89-98.

19. Albanèse J, Leone M, Alliez J-R, Kaya J-M, Antonini F, Alliez B, Martin C. Decompressive craniectomy for severe traumatic brain injury: evaluation of the effects at one year. Crit Care Med 2003;31:2535-2538.

20. Caroli M, Locatelli M, Campanella R, Balbi S, Martinelli F, Arienta C. Multiple intracranial lesions in head injury: clinical considerations, prognostic factors, management and results in 95 patients. Surg Neurol 2001;56:82-88.

21. Coplin WM, Cullen NK, Policherla PN, Vinas FC, Wilseck JM, Zafonte RD, Rengachary SS. Safety and feasibility of craniectomy with duraplasty as the initial surgical intervention for severe traumatic brain injury. J Trauma 2001;50:1050-1059.

22. Coplin WM. Intracranial pressure and surgical decompression for traumatic brain injury: biological rationale and protocol for a randomized clinical trial. Neurol Res 2001;23:277-290.

23. De Luca GP, Volpin L, Fornezza U, Cervellini P, Zanusso M, Casentini L, Curri D, Piacentino M, Bozzato G, Colombo F. 
The role of decompressive craniectomy in the treatment of uncontrollable post-traumatic intracranial hypertension. Acta Neurochir Suppl 2000;76:401-404.

24. Hutchinson PJ, Kirkpatrick PJ. Decompressive craniectomy in head injury. Curr Opin Crit Care 2004;10:101-104.

25. Jiang J-Y, Xu W, Li W-P, Xu W-H, Zhang J, Bao Y-H, Ying Y-H, Luo Q-Z. Efficacy of standard trauma craniectomy for refractory intracranial hypertension with severe traumatic brain injury: a multicenter, prospective, randomized controlled study. J Neurotrauma 2005;22:623-628.

26. Kontopoulos V, Foroglou N, Patsalas J, Magras J, Foroglou G, Yiannakou-Pephtoulidou M, Sofianos E, Anastassiou H, Tsaoussi G. Decompressive craniectomy for the management of patients with refractory hypertension: should it be reconsidered? Acta Neurochir (Wien) 2002;144:791-796.

27. Münch E, Horn P, Schürer L, Piepgras A, Paul T, Schmiedek P. Management of severe traumatic brain injury by decompressive craniectomy. Neurosurgery 2000;47:315-322.

28. Polin RS, Shaffrey ME, Bogaev CA, Tisdale N, Germanson T, Bocchicchio B, Jane JA. Decompressive bifrontal craniectomy in the treatment of severe refractory post-traumatic cerebral edema. Neurosurgery 1997;41:84-92.

29. Piek J. Decompressive surgery in the treatment of traumatic brain injury. Curr Opin Crit Care 2002;8:134-138.

30. Ruf B, Heckmann M, Schroth I, Hügens-Penzel M, Reiss I, Borkhardt A, Gortner L, Jödicke A. Early decompressive craniectomy and duraplasty for refractory intracranial hypertension in children: results of a pilot study. Crit Care 2003;7:R133-138.
31. Uhl E, Kreth FW, Elias B, Goldammer A, Hempelmann RG, Liefner M, Nowak G, Oertel M, Schmieder K, Schneider GH. Outcome and prognostic factors of hemicraniectomy for space occupying cerebral infarction. J Neurol Neurosurg Psychiatry 2004;75:270-274.

32. Winter CD, Adamides A, Rosenfeld JV. The role of decompressive craniectomy in the management of traumatic brain injury: a critical review. J Clin Neurosci 2005;12:619-623.

33. Tantawi D, Armonda R, Valerio I, Kumar AR. Management of decompressive craniectomy defects: modern military treatment strategies. J Craniofac Surg 2012;23:2042-2045.

\section{ABOUT THE AUTHORS}

\section{Hernando Raphael Alvis-Miranda}

Physician, Universidad de Cartagena, Cartagena, Colombia

\section{Gabriel Alcala-Cerra}

Resident, Department of Neurosurgery, Universidad de Cartagena Cartagena, Colombia

\section{Andres M Rubiano}

Neurosurgeon, Director de Educacion Medica (Fundacion Meditech) Hospital Universitario de Neiva, Colombia

\section{Luis Rafael Moscote-Salazar (Corresponding Author)}

Neurosurgeon, Universidad de Cartagena, Cartagena, Colombia e-mail: mineurocirujano@aol.com 